\title{
Atheroembolic Renal Disease and Anticoagulants use: A Case Report and Literature Review
}

\author{
Umabala Pasupalaa, b, Mihail Soare ${ }^{\mathrm{a}}$, Sandy Dianne ${ }^{\mathrm{a}}$, Rute Paixao ${ }^{\mathrm{a}}$, \\ Beth Fromkin ${ }^{\mathrm{a}}$, Mariana Berho ${ }^{\mathrm{a}}$, Mauro Braun ${ }^{\mathrm{a}}$
}

\begin{abstract}
Warfarin therapy is associated with improved clinical outcomes in several conditions including atrial fibrillation and thromboembolic disease. However, it can cause peripheral embolization by destabilizing the atherosclerotic plaque. This usually manifests as purple or blue toe syndrome, but isolated cases of renal manifestations are also reported. We report the case of a 77-year-old man who has been hemodialysis dependent due to warfarin induced atheroembolic renal disease. This is the most common cause of death in patients with cholesterol crystal embolization. Better understanding of the clinicopathological manifestations and high index of suspicion for the condition in predisposed patients can facilitate early diagnosis and potentially decrease the mortality risk.
\end{abstract}

Keywords: Atheroembolic renal disease; Anticoagulants; Warfarin

\section{Introduction}

Cholesterol crystal embolization (CCE) is a life threatening, multisystemic disorder. It is often under recognized, and previously described as "Cinderella of Nephrology" [1]. CCE is associated with a high mortality of up to $80 \%$. Renal involvement, described as atheroembolic renal disease (AERD) is the major cause of death $[2,3]$. Over $60 \%$ of the cases usually follow invasive procedures like angiography or vascular surgery, but it may occur spontaneously or provoked by anticoagulants and thrombolytics [4-6].

Warfarin, despite its major benefits in various clinical conditions, was among the top ten drugs to cause serious ad-

Manuscript accepted for publication October 3, 2012

a Department of Nephrology and Hypertension, Cleveland Clinic Florida, 2950 Cleveland Clinic Blvd, Weston, FL 33331, USA

${ }^{\mathrm{b}}$ Corresponding author: Umabala Pasupala, Department of Nephrology and Hypertension, Cleveland Clinic Florida, 2950 Cleveland Clinic Blvd, Weston, FL 33331, USA. Email: pasupau@ccf.org

doi: http://dx.doi.org/10.4021/wjnu37w verse events, as reported to the United States FDA during the 1990 and 2000 decades. It can cause renal impairment by different mechanisms including atheroembolism, glomerular hemorrhage, tubular obstruction by RBC casts, and acute interstitial nephritis. Warfarin was originally reported to cause purple toe syndrome by cholesterol embolization [7], and by the same mechanism it may cause AERD. We present a case of severe renal failure requiring dialysis from warfarininduced atheroembolism.

\section{Case Report}

A 77-year-old Caucasian man was referred to the emergency room due to abnormal renal function with elevated serum creatinine $(10.2 \mathrm{mg} / \mathrm{dL})$ and hyperkalemia $(6.2 \mathrm{mmol} / \mathrm{L})$. He had a history of hypertension, hyperlipidemia, paroxysmal atrial fibrillation, and also transient ischemic attack (TIA) two months prior. He was subsequently started on warfarin. The serum creatinine was $1.3 \mathrm{mg} / \mathrm{dL}$ at the time of initiation of warfarin. For the past month, he noticed worsening fatigue, dyspnea on exertion, nausea and decreased appetite. Lately he developed metallic taste and decreased urine output. He denied any skin rash or discoloration, leg pain, leg swelling, hematuria, abdominal pain and any neurologic symptoms. There were no recent invasive vascular procedures. Patient was a non-smoker, and there was no family history of kidney disease. In addition to warfarin, his current

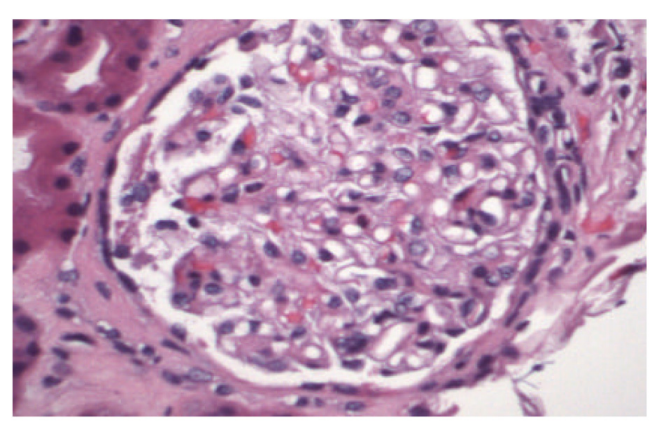

Figure 1. Mild mesangial matrix expansion, otherwise normal glomerulus (Hematoxylin \& Eosin, $\times 4,000$ ). 


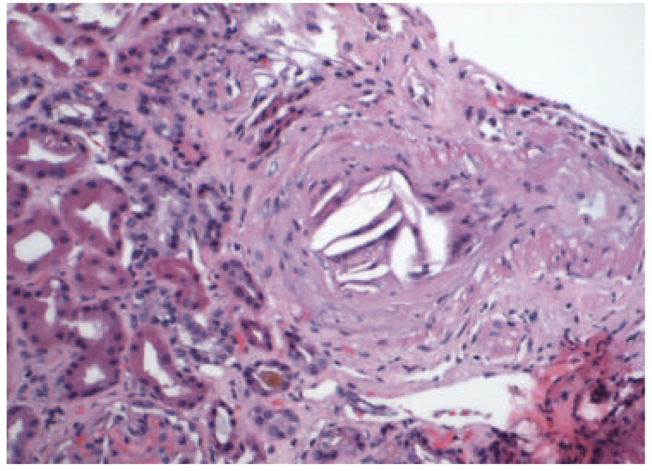

Figure 2. Medium sized artery with focal occlusion by cholesterol clefts, surrounded by granulomatous inflammation (Hematoxylin \& Eosin, × 2,000).

medications included amlodipine, atenolol and lisinopril.

Physical examination on admission was unremarkable, except for mildly elevated blood pressure of 150/74 mmHg. There was no skin rash on lower extremities. Laboratory data revealed blood urea nitrogen $(126 \mathrm{mg} / \mathrm{dL})$, serum creatinine $(11.2 \mathrm{mg} / \mathrm{dL})$, potassium $(6.9 \mathrm{mmol} / \mathrm{L})$, bicarbonate $(17$ $\mathrm{mmol} / \mathrm{L})$, eosinophilia $(11 \%)$, elevated sedimentation rate $(66 \mathrm{~mm} / \mathrm{hr})$, and C- reactive protein $(21 \mathrm{mg} / \mathrm{L})$, with normal complement levels. Urine electrolytes showed urine sodium of $59 \mathrm{mmol} / \mathrm{L}$, fractional excretion of sodium $(\mathrm{FeNa})$ of $5.65 \%$, and fractional excretion of urea nitrogen $(\mathrm{FeUN})$ of $50.32 \%$, which were consistent with intrinsic renal etiology. Urinalysis showed a bland urine sediment, and nonnephrotic range proteinuria $(582 \mathrm{mg} / 24 \mathrm{hr})$.

Renal ultrasound showed normal size kidneys with bilateral cortical thinning, and no hydronephrosis. CT scan of the abdomen and pelvis showed a $3.2 \mathrm{~cm}$ infrarenal abdominal aortic aneurysm with mural thrombus of undetermined age. Patient was started on dialysis and a percutaneous renal biopsy was performed. The biopsy specimen revealed that 8 out of 26 glomeruli were globally sclerotic and the remaining glomeruli showed diffuse mesangial matrix expansion and focal patchy interstitial fibrosis (Fig. 1). The medium sized arteries were focally occluded by cholesterol clefts surrounded by granulomatous inflammation, and small arterioles with severe arteriolonephrosclerosis, without evidence of vasculitis (Fig. 2,3). The patient was discharged home with outpatient dialysis arrangements, and he has remained dialysis dependent.

\section{Discussion}

CCE occurs after dislodgement of the atherosclerotic plaques from large sized arteries and subsequent embolization to small and medium sized arteries causing end organ ischemia by occlusion and inflammatory response [8]. It is generally seen in white men over 60 years of age, who have a history

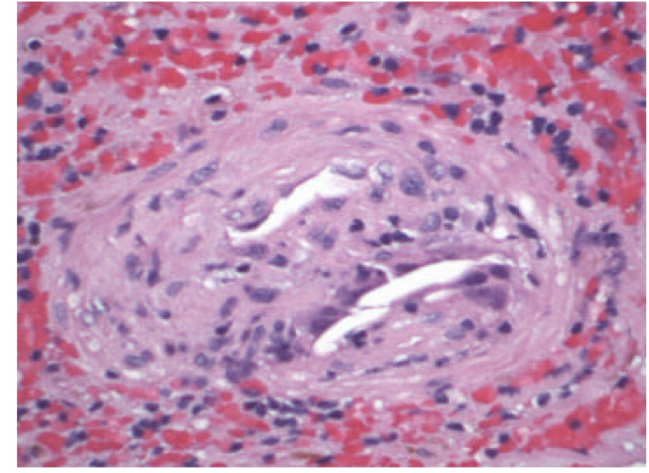

Figure 3. Cholesterol crystals surrounded by histiocytes (Hematoxylin \& Eosin, $\times$ 4,000).

of severe atherosclerosis [9]. It usually follows a triggering event, like invasive vascular procedure, but association with anticoagulants and thrombolytics has been described. It is hypothesized that warfarin may dissolve the fibrin clot or impair the fibrin thrombus formation over the ulcerated atherosclerotic plaque, leading to destabilization of the atheroma and subsequent embolization [6, 7].

The five most commonly affected organs are skin, kidneys, lower extremity skeletal muscles, gastrointestinal tract, and brain [10]. It clinically manifests as livedo reticularis, blue toe/purple toe syndrome, renal failure, abdominal pain and neurological deficits. In the kidney, it primarily affects the arcuate and interlobar arteries, and can present as acute, subacute or chronic renal impairment $[10,11]$. Renal involvement is seen in more than $50 \%$ of the cases, with progression to dialysis in $28-61 \%$, and 1 year mortality rate up to $83 \%$ [12]. AERD was noted in $7.1 \%$ of 259 patients, who are above 60 years and underwent renal biopsy for acute renal failure [13]. This shows that AERD is not an uncommon cause of acute kidney injury in elderly patients. The cholesterol crystals can trigger an inflammatory cascade leading to constitutional symptoms of fever, fatigue, anorexia, weight loss, and myalgias. Eosinophilia, elevated ESR, CRP and hypocomplementemia can also be present. Hollenhorst plaques on fundoscopy due to retinal embolization have been described as a telltale sign of CCE [14]. The definitive diagnosis relies on biopsy of the target organ, and demonstration of the transparent, biconvex, needle shaped cholesterol clefts.

There is no specific treatment for AERD except for supportive measures for the end organ damage, and controlling the modifiable risk factors for atherosclerosis. Measures such as controlling the blood pressure and inhibiting the renin agiotensin system with angiotensin converting enzyme inhibitors or angiotensin receptor blockers are often indicated. The use of statins and antiplatelet agents may be beneficial $[11,15,16]$, although controlled data is lacking. If possible, discontinuation of the anticoagulation is recommended [17]. Improvement in the condition despite continuation of the anticoagulation has also been reported $[18,19]$. One needs to 
make a decision regarding anticoagulation on a case by case analysis by considering the risks and benefits, especially in elderly people with preexisting severe atherosclerosis. In our patient, given his history of atrial fibrillation and recent TIA, anticoagulation was continued.

\section{Conclusion}

Atheroembolic renal disease is a dreaded complication of cholesterol embolization, without specific curative measures to date. Warfarin may play a role in inciting the condition by destabilizing the atheroma. However it may not be practical to avoid or withhold its use to prevent the condition, as it may result in other serious life threatening consequences. When initiating patients on anticoagulation, it is important for the caregivers to have high index of suspicion combined with periodic renal function monitoring to diagnose AERD in its earlier stages.

\section{Conflicts of Interest}

No conflict of interest was declared by the authors in regard to this work.

\section{References}

1. Scoble JE, O'Donnell PJ. Renal atheroembolic disease: the Cinderella of nephrology? Nephrol Dial Transplant. 1996;11(8):1516-1517.

2. Fine MJ, Kapoor W, Falanga V. Cholesterol crystal embolization: a review of 221 cases in the English literature. Angiology. 1987;38(10):769-784.

3. Scolari F, Ravani P, Gaggi R, Santostefano M, Rollino C, Stabellini N, Colla L, et al. The challenge of diagnosing atheroembolic renal disease: clinical features and prognostic factors. Circulation. 2007;116(3):298-304.

4. Lye WC, Cheah JS, Sinniah R. Renal cholesterol embolic disease. Case report and review of the literature. Am J Nephrol. 1993;13(6):489-493.

5. Queen M, Biem HJ, Moe GW, Sugar L. Development of cholesterol embolization syndrome after intravenous streptokinase for acute myocardial infarction. Am J Car- diol. 1990;65(15):1042-1043.

6. Nevelsteen A, Kutten M, Lacroix H, Suy R. Oral anticoagulant therapy: a precipitating factor in the pathogenesis of cholesterol embolization? Acta Chir Belg. 1992;92(1):33-36.

7. Hyman BT, Landas SK, Ashman RF, Schelper RL, Robinson RA. Warfarin-related purple toes syndrome and cholesterol microembolization. Am J Med. 1987;82(6):1233-1237.

8. Moldveen-Geronimus M, Merriam JC, Jr. Cholesterol embolization. From pathological curiosity to clinical entity. Circulation. 1967;35(5):946-953.

9. Saklayen MG. Atheroembolic renal disease: preferential occurrence in whites only. Am J Nephrol. 1989;9(1):8788.

10. Kronzon I, Saric M. Cholesterol embolization syndrome. Circulation. 2010;122(6):631-641.

11. Meyrier A. Cholesterol crystal embolism: diagnosis and treatment. Kidney Int. 2006;69(8):1308-1312.

12. Scolari F, Tardanico R, Zani R, Pola A, Viola BF, Movilli E, Maiorca R. Cholesterol crystal embolism: A recognizable cause of renal disease. Am J Kidney Dis. 2000;36(6):1089-1109.

13. Haas M, Spargo BH, Wit EJ, Meehan SM. Etiologies and outcome of acute renal insufficiency in older adults: a renal biopsy study of 259 cases. Am J Kidney Dis. 2000;35(3):433-447.

14. Hollenhorst RW. Significance of bright plaques in the retinal arterioles. JAMA. 1961;178:23-29.

15. Jucgla A, Moreso F, Muniesa C, Moreno A, Vidaller A. Cholesterol embolism: still an unrecognized entity with a high mortality rate. J Am Acad Dermatol. 2006;55(5):786-793.

16. Belenfant X, Meyrier A, Jacquot C. Supportive treatment improves survival in multivisceral cholesterol crystal embolism. Am J Kidney Dis. 1999;33(5):840850.

17. Vidt DG. Cholesterol emboli: a common cause of renal failure. Annu Rev Med. 1997;48:375-385.

18. Wakabayashi T, Yoshizawa Y, Kawana S. Successful use of heparin and warfarin in the treatment of cholesterol crystal embolization. J Dermatol. 2008;35(2):111-114.

19. Moll S, Huffman J. Cholesterol emboli associated with warfarin treatment. Am J Hematol. 2004;77(2):194-195. 